\title{
Functional-Anatomic Correlates of Control Processes in Memory
}

\author{
Randy L. Buckner \\ Department of Psychology, Howard Hughes Medical Institute at Washington University, St. Louis, Missouri 63130
}

\section{Introduction}

A central role for control processes in long-term memory is apparent when one considers that there is far more information available in memory than can be accessed at any single moment (Tulving and Pearlstone, 1966; Koriat, 2000). Much as selective attention operates to focus processing on objects in the environment, related control processes are required to constrain and select from information stored in memory.

Neuroimaging studies have expanded our understanding of control processes in long-term memory in three important ways. First, networks of regions, prominently including specific regions in prefrontal cortex, contribute to control processes during memory retrieval. Dissociations among regions suggest a functional-anatomic gradient with posterior frontal regions contributing to domain-specific control processes (e.g., verbal versus nonverbal) and anterior regions contributing to abstracted control processes that generalize across informational domains. Second, through convergent exploration of other cognitive task forms such as working memory, findings suggest that frontally mediated control processes are important to a wide range of task contexts that include, but extend beyond, long-term memory retrieval. Finally, study of these networks in aging has identified two candidate mechanisms by which their disruption may contribute to, or compensate for, cognitive decline. Evidence for these three sets of findings are presented as examples of how neuroimaging methods have contributed to explorations of higher-level cognition.

\section{Specific frontal regions contribute to control processes}

Control processes are central to memory retrieval. Defined broadly, control processes are intentional processes initiated by a subject to solve a task. Control processes have certain properties; they require sequential steps of processing, are capacity limited, and tend to operate in situations in which the task goal cannot be met through automated stimulus-response mappings (Schneider and Shiffrin, 1977). The need for control processes in memory arises because the vast amount of information stored in memory far exceeds the specific information that is required at any given moment. Control processes are therefore required to search, select, and monitor information during acts of retrieval.

Damage to frontal cortex in humans can cause difficulties

This work was supported by the National Institutes of Health (MH57506), the James S. McDonnell Foundation (99-63/9900003), the Alzheimer's Association, and the Howard Hughes Medical Institute. I thank Steve Petersen for valuable discussion and Cindy Lustig, Mark Wheeler, Anthony Fotenos, Luigi Maccotta, Denise Head, Brian Gold, Jim Kelly, and Marc Raichle for comments.

Correspondence should be addressed to Dr. Randy L. Buckner, Department of Psychology, Howard Hughes Medical Institute at Washington University, One Brookings Drive, Campus Box 1125, St. Louis, M0 63130. E-mail: rbuckner@artsci.wustl.edu.

Copyright $\odot 2003$ Society for Neuroscience $\quad$ 0270-6474/03/233999-06\$15.00/0 when memory retrieval requires flexible use of control processes (Milner et al., 1985; Schacter, 1987; Shimmamura et al., 1991). In many cases, patients will fail to recall, or sometimes even recognize, information (for review, see Wheeler et al., 1995) or inappropriately estimate the source or timing, or both, of a past episode (for review, see Schacter, 1987). In rare cases, a patient may make up episodes from the past while believing they really happened, a phenomenon called "confabulation" (Moscovitch, 1989; Burgess and Shallice, 1996). Unlike purer forms of amnesia, which result from medial temporal and diencephalic lesions (Scoville and Milner, 1957; Squire, 1992; Cohen and Eichenbaum, 1993), the deficits after frontal damage align more to improper execution of retrieval strategies (Incisa della Rocchetta and Milner, 1993). Convergent with these patient observations, acts of retrieval in healthy individuals, studied with neuroimaging methods, almost always show activation of frontal cortex (among other regions). Frontal activation has been associated with retrieval of words, sentences, faces, pictures, and in quite different retrieval task contexts (for review, see Tulving et al., 1994; Buckner, 1996; Fletcher et al., 1997; Cabeza and Nyberg, 2000).

Expanding beyond these general observations, functional imaging results have placed constraints on both the anatomic specificity of regions within frontal cortex that associate with memory and also their dissociated functional roles. Anatomically, regions that are activated include those along the left inferior frontal gyrus (particularly for verbal materials) extending anteriorally into middle frontal gyrus [near Brodmann's areas (BA) 44, 45, and 47]. Regions near the frontal poles (near BA 10) have also been observed consistently in imaging studies (Fig. 1).

The functional roles of these several regions can be dissociated on multiple dimensions that obey a roughly posterior to anterior gradient [see also Petrides et al. (1995)]. Posterior frontal regions tend to show lateralization depending on whether verbal or nonverbal materials are being retrieved, suggesting domain specificity (Wagner et al., 1998; McDermott et al., 1999). By contrast, more anterior regions tend to exhibit complex properties dependent on higher-order task processes. For example, activation patterns in anterior regions near BA 44/45 and 47 suggest a role in dynamic access and selection during retrieval. Several studies, conducted in various contexts that involve retrieving and categorizing words, illustrate this point.

Petersen and colleagues (1989) noted robust activation in left anterior prefrontal cortex during retrieval of verbs cued by nouns (e.g., retrieving "walk" in response to "dog") but considerably less activation when subjects simply read the nouns. Controlled processes are required during verb retrieval in this context because the target word is not the automatic associate of the presented noun; it must be sought and selected from many possible 


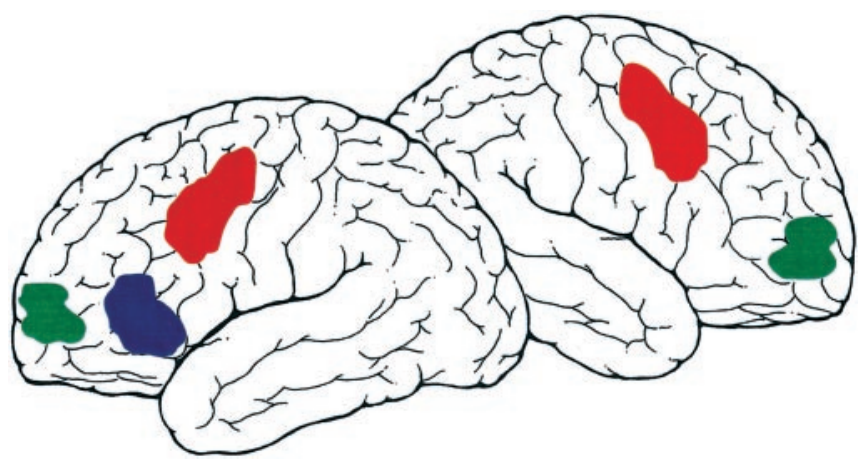

Figure 1. Frontal regions activated during memory retrieval show a roughly posterior to anterior gradient of functional specialization. Posterior regions (red) tend to modulate on the basis of retrieved content, and more anterior regions (blue) modulate based on the level and type of controlled processing demand. Frontal-polar regions (green) exhibit complex properties that are content independent and associated with high-level task goals (see text).

alternatives within memory. Single word reading, by contrast, is an automated task that requires minimal controlled processing because the association of a word's sound to its visual form is overlearned through extensive experience. When verb retrieval is practiced, allowing for rapid but more stereotyped retrieval, activation in these frontal regions diminishes substantially (Raichle et al., 1994). As another example, categorizing a word within an arbitrary grouping (e.g., abstract versus concrete), which requires retrieval of its context-relevant meaning, also encourages considerable recruitment (Demb et al., 1995). By contrast, classifying the alphabetic order of the letters in a word, which is a timeconsuming task but nonetheless based on invariant informational properties, does not (Demb et al., 1995; see also Gold and Buckner, 2002).

In the context of remembering episodes, recalling the details of an earlier event elicits strong activation in anterior prefrontal regions, whereas simply recognizing whether a presented cue word is old or new shows less activation (Nolde et al., 1998; Dobbins et al., 2002). Konishi et al. (2002), building from earlier neuropsychological paradigms (Milner et al., 1991), recently noted enhanced activation in prefrontal regions when the difficulty in recalling the details of an earlier episode was increased. Within the perceptual domain, Ranganath et al. (2000) observed that left anterior prefrontal cortex increased activation as the level of perceptual detail required at the time of retrieval was increased. Wheeler and Buckner (2003) noted similarly that within the context of retrieving source details, left anterior prefrontal cortex will be more active if the to-be-retrieved information is studied minimally, requiring the subject to devote more extensive controlled processing during retrieval, than when the information is studied repeatedly.

The prevailing interpretation of these results is that frontal regions along BA 44/45/47 participate when a novel or weakly associated representation must be momentarily constructed to solve a task goal, at the exclusion of other possible, but contextinappropriate, representations (Goldman-Rakic, 1987; ThompsonSchill et al., 1997; Mesulam, 2002; see also Duncan and Owen, 2000; Fletcher et al., 2000; Miller, 2000; Gold and Buckner, 2002). Situations in which past experience or invariant rules allow a cue to directly specify the needed representation do not appear to require these anterior prefrontal regions.

The relevance to memory retrieval is that in many retrieval contexts the sought representation is often guided, but not directly specified, by cues in the environment. These anterior re- gions, through poorly understood mechanisms, appear to contribute to the dynamic selection of representations during longterm memory retrieval, possibly through interactions with posterior regions in temporal and parietal cortex that serve as storage sites. Because remembering requires more detailed, or weakly associated, information to be retrieved, frontal participation in control processes increases. Convergent with this idea, when these (or nearby) frontal regions are damaged, patients can have difficulties selecting appropriate representations. Patients with left frontal lesions, for example, are impaired on free recall in a manner that is consistent with impaired use of retrieval strategies (Incisa della Rocchetta and Milner, 1993). More broadly, patients with frontal lesions can show source memory impairment (Schacter, 1987) and also retrieval impairment on a wide range of other task forms, with the greatest deficits found during free recall in which minimal cues are available, and the most modest deficits found during simple recognition tests in which complete retrieval cues are provided (Wheeler et al., 1995).

\section{Frontal-polar regions contribute to control processes associated with ongoing task modes}

Perhaps the most novel and perplexing finding to emerge from neuroimaging research on memory retrieval is that frontal-polar regions, often right lateralized, are differentially activated during episodes of remembering (for review, see Tulving et al., 1994; Buckner, 1996). Other forms of retrieval show considerably less activation. For example, frontal-polar regions activate minimally when a subject retrieves any word beginning with a certain stem cue (e.g., generating "street" in response to "str "), but if the task requires using the stem cue to remember from a specific earlier study list of words, robust activation is observed (Squire et al., 1992). Frontal-polar regions are also dissociated from other frontal regions because they do not modulate across verbal/nonverbal domain lines being right-lateralized for retrieval of both word and faces (McDermott et al., 1999). Despite these observations, it has been surprisingly difficult to specify the nature of frontal-polar contributions to remembering.

One puzzle is that the ability to detect frontal-polar activation in imaging studies is greatly influenced by the structure of the memory paradigm and the exact time frame over which activity is recorded. Early paradigms, because of their methodological limitations, averaged activity over extended time periods during which many retrieval events were performed in rapid succession (Squire et al., 1992). Right frontal-polar activity was almost always observed during remembering in these studies (Buckner, 1996). By contrast, more recent "event-related" paradigms that explore activity aligned to individual retrieval trials less often note right frontal-polar activity or note activity patterns that are considerably extended in time (Schacter et al., 1997; Henson et al., 2000).

A possible, but unanticipated, interpretation of this data pattern is that frontal-polar cortex may contribute to form an attentional set, or task mode, that extends over multiple individual retrieval events (Nyberg et al., 1995; Düzel et al., 1999) (Fig. 2). Preliminary evidence, based on a paradigm that can separate temporally extended activity correlates from those aligned to individual events (Donaldson et al. 2001), suggests that right frontal-polar contributions to memory retrieval are associated almost entirely with mode-related processes (Wheeler et al., 2002). More studies will be required to explore this speculative possibility and also to determine the generality of the finding. Many kinds of systems require state-dependent gating such that information is handled differently depending on operational 

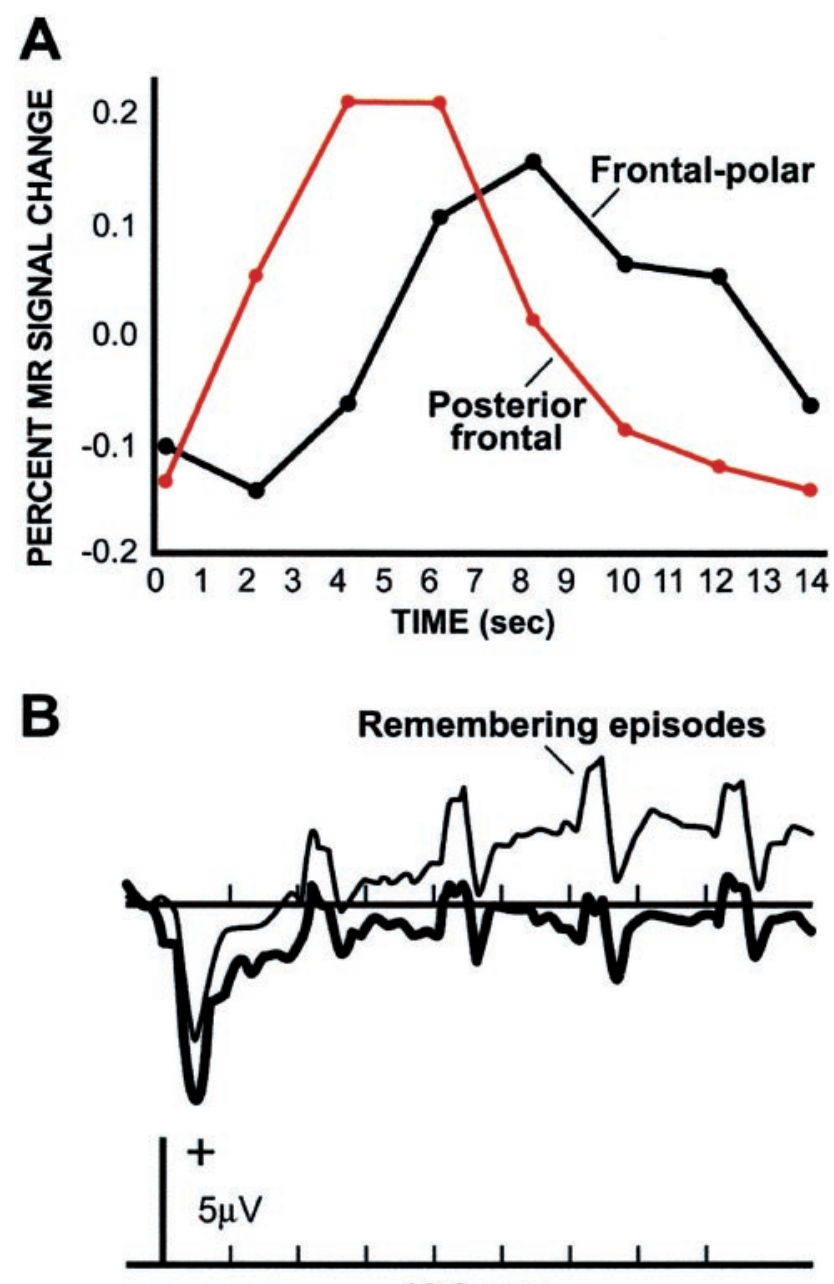

$10.0 \mathrm{sec}$

Figure 2. During retrieval of specific episodes, frontal-polar regions demonstrate prolonged signal change, suggesting a contribution to temporally extended processes that establish a task set or retrieval mode. $A$, The time course of posterior and anterior frontal regions is shown from a functional magnetic resonance imaging study of memory retrieval. Note that the timescale (in seconds) reflects the temporal blurring of the hemodynamic response (Logethetis, 2003). Adapted from Schacter et al. (1997). B, The time course of evoked response potentials measured over anterior frontal scalp sites. A slowly evolving change in the waveform is noted during the periods of remembering that extends across individual items. Adapted from Düzel et al. (1999).

mode. Frontal-polar cortex may contribute to gating processes in the cognitive domain, helping to maintain cognitive sets during remembering, and other forms of cognitive task that select one mode of processing over another across extended periods of time.

\section{Frontal contributions to control processes generalize across} many task domains

Traditional investigations of brain structures associated with memory have most often sought to discover brain areas or physiological processes specific to memory that dissociate from other kinds of cognitive operation. The still-in-progress 40 year journey to understand the role of medial temporal regions to memory is perhaps the best example (Corkin, 2002). After medial temporal removal, other kinds of cognition are relatively sparred but profound memory impairments result (Scoville and Milner, 1957; Squire, 1992; Cohen and Eichenbaum, 1993). Such an observation suggests that medial temporal structures have evolved to be specialized for solving a limited set of computational problems associated primarily with memory.
Results from recent neuroimaging studies have illustrated that frontal contributions to memory fall at the other end of the evolutionary spectrum. Frontal regions associated with memory retrieval are likely general computational resources that allow selection and control of context-appropriate representations in many task contexts. Neuroimaging studies are particularly powerful for providing insight into convergent uses of brain regions in cognition. This is because, independent of the investigator's anatomic focus, large portions of the cerebral cortex are typically surveyed in most studies, allowing unexpected, empirically derived regularities to emerge.

One such emergent observation is that task forms with many different goals encourage participation of similar anterior frontal and frontal-polar regions. Specifically considering the left anterior region near BA 44/45/47, tasks putatively targeting working memory, long-term memory encoding, speech generation, and long-term retrieval all show strong activation [for similar discussion, see Duncan and Owen (2000)]. Thus, the common underlying operation important to long-term retrieval also appears important to tasks with other immediate goals. Frontal-polar contributions to remembering are also likely derived from more general processing resources. Frontal-polar cortex, in addition to activating during epochs of tasks associated with remembering, activates during tasks that require multiple competing task goals and also during certain (but not all) tasks involving working memory (MacLeod et al., 1998; Koechlin et al., 1999; Strange et al., 2001; Braver and Bongiolatti, 2002; Nyberg et al., 2002).

Anterior and frontal-polar regions associated with control processes thus appear to make their contributions at abstract levels detached from particular modalities and specific task goals. One common theme among ideas regarding left anterior frontal cortex near BA 44/45/47 is that it participates in constraining and selecting representations when cues do not directly (automatically) specify the needed response (Thompson-Schill et al., 1997; Duncan and Owen, 2000; Fletcher et al., 2000; Gold and Buckner, 2002), an idea that resonates with findings from studies of human patients (Mesulam, 2002) and animal models (Goldman-Rakic, 1987; Miller, 2000). However, this general idea will need to be expanded further to include the kinds of unanticipated properties exhibited by frontal-polar cortex, which appear associated with broad control of task processes that extend over time and over individual task events.

Older adults fail to appropriately recruit frontal regions associated with control processes

Older adults, even those free from signs of clinical dementia, often experience mild forgetfulness and difficulties on tasks that require selective attention (Craik, 1977; Zacks and Hasher, 1994; Moscovitch and Winocur, 1995; Balota et al., 2000). Neuroimaging studies, taking advantage of their ability to compare functional anatomy between populations, are well positioned to unravel possible reasons for cognitive decline. Two forms of change associated with recruitment of frontal resources have been reliably observed in older adults and provide targets for further exploration. These two forms of change are here referred to as under-recruitment and nonselective recruitment (Fig. 3).

In many task contexts, older adults do not fully activate frontal regions to the same degree as younger adults (underrecruitment) (Grady et al., 1995; Cabeza et al., 1997; Logan et al., 2002). The most consistent example of this phenomenon occurs in studies of encoding when information is intentionally committed to memory. During intentional memorization, younger adults spontaneously recruit multiple frontal regions, including 
the left anterior frontal regions discussed above (Kapur et al., 1996). Such a finding is not surprising given that verbal elaboration is an effective memorization strategy, and these frontal regions are used to flexibly retrieve words and their meanings. Of interest, older adults do not fully recruit these frontal regions during intentional memorization, and memory performance is often decreased (Grady et al., 1995; Logan et al., 2002). For example, Grady and colleagues (1995) imaged older adults memorizing faces. Although activation in many regions was comparable between older and younger adults, regions in frontal cortex were significantly reduced. A first, obvious concern is that underrecruitment might be an artifact of population characteristics that confound measurement using neuroimaging methods. Control studies suggest that this confound is unlikely (D'Esposito et al., 1999; Buckner et al., 2000; Huettel et al., 2001). The more likely explanation is that older adults fail to spontaneously engage frontal regions important to memorization, which in turn leads to memory difficulties.

A second form of recruitment difference between young and old adults is nonselective recruitment. Older adults, paradoxically, often recruit frontal regions that are minimally active when younger adults perform the same tasks (Cabeza et al., 1997; Madden et al., 1999; ReuterLorenz et al., 2000; Logan et al., 2002). For example, in task situations in which strongly left-lateralized prefrontal recruitment is observed in younger adults, such as during tasks requiring extensive verbal processing, older adults show bilateral recruitment (Reuter-Lorenz et al., 2000; Logan et al., 2002).

The consequences of nonselective recruitment to cognitive processing are a hotly debated topic. Patients with brain lesions often activate atypical regions, a finding most often attributed to compensation. Older adults, in the presence of diminishing resources, may similarly recruit additional regions as a form of compensation (Cabeza et al., 2002; Reuter-Lorenz, 2002). A compensation hypothesis predicts that nonselective recruitment is a beneficial response. A second, nearly opposite possibility is that nonselective recruitment itself represents the breakdown in appropriate control processes across cortical regions. This latter possibility predicts that nonselective recruitment will eventually be discovered to be the outcome of (and not compensatory for) a detrimental physiological cascade that accompanies aging in some individuals.

One candidate mechanism that might underlie nonselective recruitment, or cause a compensatory response that leads to nonselective recruitment, relates to age-associated change in whitematter integrity. Older adults often show damage to white matter surrounding the ventricles; diffusion tensor imaging has further implicated breakdown of the corpus collosum (Raz, 2000; O'Sullivan et al., 2001). These white-matter changes tend to be preferential for anterior brain regions and most pronounced in
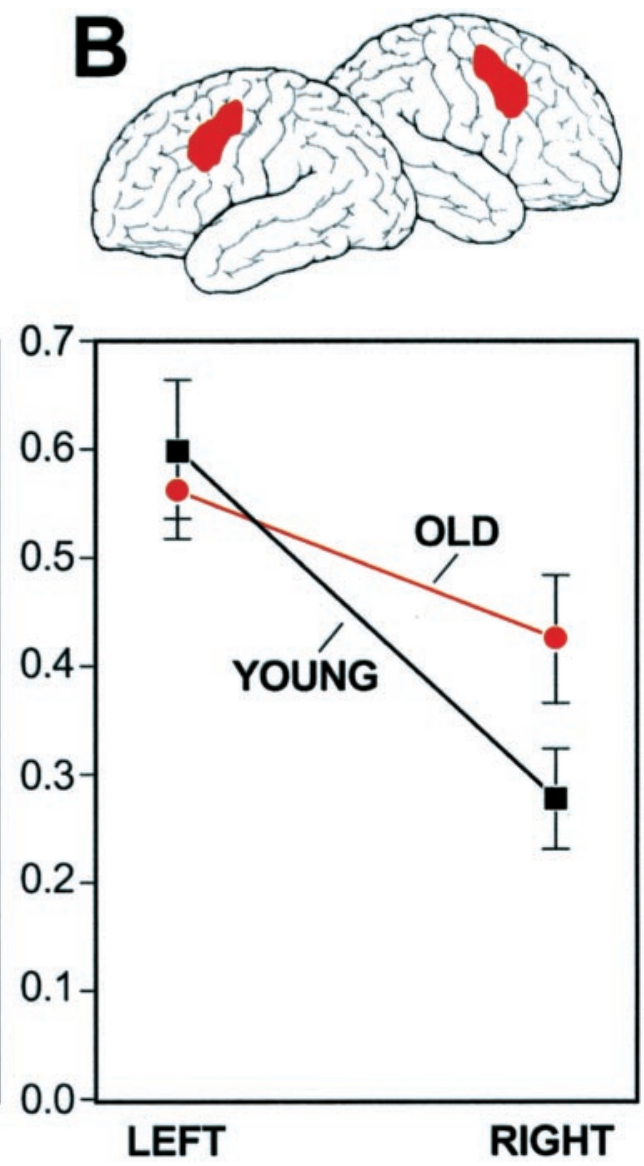

Figure 3. Under-recruitment and nonselective recruitment of frontal regions in older adults are illustrated. $A$, Anterior left Older adults show greater relative activation of the homologous right frontal region. Adapted from Logan et al (2002). See Cabeza (2002) and Reuter-Lorenz (2002) for additional examples.

individuals with vascular compromise (e.g., hypertension). One possibility is that breakdown in white matter leads to disrupted connectivity between frontal and other cortical regions that, in turn, undermines the cortical control of task processes. Attentional and mild memory difficulties so often associated with aging may be the result (Craik, 1977; Zacks and Hasher, 1994; Moscovitch and Winocur, 1995; Balota et al., 2000). Alternative underlying mechanisms are also plausible. Change in neurotransmitter properties (e.g., dopamine receptor mechanisms), and not integrity of white matter, may associate with nonselective recruitment and cognitive decline (Arnsten et al., 1994; Braver et al., 2002). Age-associated disruption in basal ganglia function, which could in turn change prefrontal recruitment, is also a possibility (Rubin, 1999).

Work to resolve this debate and describe underlying causal mechanisms is currently underway in a number of laboratories. Methods beyond those afforded by functional neuroimaging will be required for progress, such as the use of animal models of aging (Arnsten et al., 1994; Barense et al., 2002; Winocur and Moscovitch, 1990). The finding of nonselective recruitment as a phenomenon in aging, which has now been reported in $>10$ independent studies (for review, see Cabeza, 2002; ReuterLorenz, 2002), illustrates the kind of observation that neuroimaging methods are well suited to provide. 


\section{Conclusions}

Memory depends on processes that allow information to endure over time and also on processes enabling efficient retrieval at just the right moment. Studies of patients with frontal lesions have long supported a role of frontal cortex in strategic aspects of memory. Neuroimaging studies have recently provided insights into the anatomic specificity of frontal contributions to retrieval and also suggested constraints on the nature of the contributions.

Findings suggest a posterior to anterior gradient within prefrontal cortex, with posterior regions participating in domainspecific processes (e.g., verbal versus nonverbal) and more anterior prefrontal regions participating in high-level control processes that generalize across modality and even specific task goals. Perhaps most novel, findings suggest that frontal-polar regions participate in forms of control process that extend over time and individual processing events. One speculation is that frontal-polar regions participate in maintaining contextappropriate attentional sets, or modes, during remembering and other forms of complex cognitive acts.

Our fledgling understanding of these processes, and the broad posterior to anterior functional gradient that has emerged, also encourages us to seek convergence and constraints from others methods. For example, better human functional-anatomic characterization will likely require more detailed knowledge of connectivity between human brain areas and fine-grained functional analysis of subregions within prefrontal cortex that may not be possible with currently available imaging methods.

Recent results have also identified age-associated changes in the recruitment of frontal regions that may contribute to, or aid to alleviate, cognitive decline in older adults. Two recruitment differences have been observed, heuristically referred to as underrecruitment and nonselective recruitment. Although the underlying causes of recruitment differences remain a mystery, their discovery and replication across many studies encourage new questions to be asked.

\section{References}

Arnsten AFT, Cai JX, Murphy BL, Goldman-Rakic PS (1994) Dopamine D-1 receptor mechanisms in the cognitive performance of young-adult and aged monkeys. Psychopharmacology 116:143-151.

Balota DA, Dolan PO, Duchek JM (2000) Memory changes in healthy older adults. In: The Oxford handbook of memory (Tulving E, Craik FIM, eds), pp 395-410. New York: Oxford UP.

Barense MD, Fox MT, Baxter MG (2002) Aged rats are impaired on an attentional set-shifting task sensitive to medial frontal cortex damage in young rats. Learn Mem 9:191-201.

Braver TS, Bongiolatti SR (2002) The role of frontopolar cortex in subgoal processing during working memory. NeuroImage 15:523-536.

Braver TS, Barch DM, Keys BA, Carter CS, Cohen JD, Kaye JA, Janowsky JS, Taylor SF, Yesavage JA, Munenthaler MS, Jagust WJ, Reed BR (2002) Context processing in older adults: evidence for a theory relating cognitive control to neurobiology in healthy aging. J Exp Psychol 130:746-763.

Buckner RL (1996) Beyond HERA: contributions of specific prefrontal brain areas to long-term memory retrieval. Psychonomic Bull Rev 3:149-158.

Buckner RL, Snyder AZ, Sanders AL, Raichle ME, Morris JC (2000) Functional brain imaging of young, nondemented, and demented older adults. J Cognit Neurosci 12[Suppl 2]:24-34.

Burgess PW, Shallice T (1996) Confabulation and the control of recollection. Memory 4:359-411.

Cabeza R (2002) Hemispheric asymmetry reduction in older adults: the HAROLD model. Psychol Aging 17:85-100.

Cabeza R, Nyberg L (2000) Imaging cognition II: An empirical review of 275 PET and fMRI studies. J Cognit Neurosci 12:1-47.

Cabeza R, Grady CL, Nyberg L, McIntosh AR, Tulving E, Kapur S, Jennings JM, Houle S, Craik FIM (1997) Age-related differences in neural activity during memory encoding and retrieval: a positron emission tomography study. J Neurosci 17:391-400.

Cabeza R, Anderson ND, Locantore JK, McIntosh AR (2002) Aging gracefully: compensatory brain activity in high-performing older adults. NeuroImage 17:1394-1402.

Cohen NJ, Eichenbaum H (1993) Memory, amnesia, and the hippocampal system. Cambridge, MA: MIT.

Corkin S (2002) What's new with the amnesic patient HM? Nat Rev Neurosci 3:153-160.

Craik FIM (1977) Age differences in human memory. In: Handbook of the psychology of aging (Birren JE, Warner Schaie K, eds), pp 384-420. New York: Van Nostrand Reinhold.

Demb JB, Desmond JE, Wagner AD, Vaidya CJ, Glover GH, Gabrieli JDE (1995) Semantic encoding and retrieval in the left inferior prefrontal cortex: a functional MRI study of task difficulty and process specificity. J Neurosci 15:5870-5878.

D’Esposito M, Zarahn E, Aguirre GK, Rypma B (1999) The effect of normal aging on the coupling of neural activity to the BOLD hemodynamic response. NeuroImage 10:6-14.

Dobbins IG, Foley H, Schacter DL, Wagner AD (2002) Executive control during episodic retrieval: multiple prefrontal processes subserve source memory. Neuron 35:989-996.

Donaldson DI, Petersen SE, Ollinger JM, Buckner RL (2001) Dissociating state and item components of recognition memory using fMRI. NeuroImage 13:129-142.

Duncan J, Owen AM (2000) Common regions of the human frontal lobe recruited by diverse cognitive demands. Trends Neurosci 23:475-483.

Düzel E, Cabeza R, Picton TW, Yonelinas AP, Scheich H, Heinze HJ, Tulving E (1999) Task-related and item-related brain processes of memory retrieval. Proc Natl Acad Sci USA 96:1794-1799.

Fletcher PC, Frith CD, Rugg MD (1997) The functional neuroanatomy of episodic memory. Trends Neurosci 20:213-218.

Fletcher PC, Shallice T, Dolan R (2000) Sculpting the response space-an account of left prefrontal activation at encoding. NeuroImage 12:404-417.

Gold BT, Buckner RL (2002) Common prefrontal regions co-activate with dissociable posterior regions during controlled semantic and phonological tasks. Neuron 35:803-812.

Goldman-Rakic PS (1987) Circuitry of primate prefrontal cortex and regulation of behavior by representational memory. In: Handbook of Physiology: the nervous system, Vol 5 (Plum F, Mountcastle V, eds), pp 373417. Baltimore: Williams \& Wilkins.

Grady CL, McIntosh AR, Horwitz B, Maisog JM, Ungerleider LG, Mentis MJ, Pietrini P, Schapiro MB, Haxby JV (1995) Age-related reductions in human recognition memory due to impaired encoding. Science 269:218-221.

Henson RNA, Rugg MD, Shallice T, Dolan RJ (2000) Confidence in recognition memory for words: dissociating right prefrontal roles in episodic retrieval. J Cognit Neurosci 12:913-923.

Huettel SA, Singerman JD, McCarthy G (2001) The effects of aging upon the hemodynamic response measured by functional MRI. NeuroImage 13:161-175.

Incisa della Rocchetta A, Milner B (1993) Strategic search and retrieval inhibition: the role of the frontal lobes. Neuropsychologia 31:503-524.

Kapur S, Tulving E, Cabeza R, McIntosh AR, Houle S, Craik FIM (1996) The neural correlates of intentional learning of verbal materials: a PET study in humans. Cognit Brain Res 4:243-249.

Koechlin E, Basso G, Pietrini P, Panzer S, Grafman J (1999) The role of the anterior prefrontal cortex in human cognition. Nature 399:148-151.

Koriat A (2000) Control processes in remembering. In: The oxford handbook of memory (Tulving E, Craik FIM, eds), pp 333-346. New York: Oxford UP.

Logan JM, Sanders AL, Snyder AZ, Morris JC, Buckner RL (2002) Underrecruitment and non-selective recruitment: dissociable neural mechanisms associated with aging. Neuron 33:827-840.

Logothetis NK (2003) The underpinnings of the BOLD fMRI signal. J Neurosci 23:3963-3968.

Madden DJ, Turkington TG, Provenzale JM, Denny LL, Hawk TC, Gottlob LR, Coleman RE (1999) Adult age differences in the functional neuroanatomy of verbal recognition memory. Hum Brain Mapp 7:115-135.

MacLeod AK, Buckner RL, Miezin FM, Petersen SE, Raichle ME (1998) 
Right anterior prefrontal cortex activation during semantic monitoring and working memory. NeuroImage 7:41-48.

McDermott KB, Buckner RL, Petersen SE, Kelley WM, Sanders AL (1999) Set- and code-specific activation in the frontal cortex: an fMRI study of encoding and retrieval of faces and words. J Cognit Neurosci 11:631-640.

Mesulam M-M (2002) The human frontal lobes: transcending the default mode through contingent encoding. In: Principles of frontal lobe function (Stuss DT, Knight RT, eds), pp 8-31. New York: Oxford UP.

Miller EK (2000) The prefrontal cortex and cognitive control. Nat Rev Neurosci 1:59-65.

Milner B, Petrides M, Smith ML (1985) Frontal lobes and the temporal organization of memory. Hum Neurobiol 4:137-142.

Milner B, Corsi P, Leonard G (1991) Frontal-lobe contribution to recency judgments. Neuropsychologia 29:601-618.

Moscovitch M (1989) Confabulation and the frontal systems: strategic versus associated retrieval in neuropsychological theories of memory. In: Varieties of memory and consciousness: essays in honour of Endel Tulving (Roediger III HL, Craik FIM, eds), pp 133-155. Hillsdale, NJ: Lawrence Erlbaum.

Moscovitch M, Winocur G (1995) Frontal lobes, memory, and aging. Ann NY Acad Sci 769:119-150.

Nolde SF, Johnson MK, D’Esposito M (1998) Left prefrontal activation during episodic remembering: an event-related fMRI study. NeuroReport 9:3509-3514

Nyberg L, Tulving E, Habib R, Nilsson LG, Kapur S, Houle S, Cabeza R, McIntosh AR (1995) Functional brain maps of retrieval mode and recovery of episodic information. NeuroReport 7:249-252.

Nyberg L, Forkstam C, Petersson KM, Cabeza R, Ingvar M (2002) Brain imaging of human memory systems: between-systems similarities and within-systems differences. Cognit Brain Res 13:281-292.

O'Sullivan M, Jones DK, Summers PE, Morris RG, Williams SCR, Markus HS (2001) Evidence for cortical "disconnection" as a mechanism of agerelated cognitive decline. Neurology 57:632-638.

Petersen SE, Fox PT, Posner MI, Mintun M, Raichle ME (1989) Positron emission tomographic studies of the processing of single words. J Cognit Neurosci 1:153-170.

Petrides M, Alivisatos B, Evans AC (1995) Functional activation of the human ventrolateral frontal cortex during mnemonic retrieval of verbal information. Proc Natl Acad Sci USA 92:5803-5807.

Raichle ME, Fiez JA, Videen TO, MacLeod AMK, Pardo JV, Fox PT, Petersen SE (1994) Practice-related changes in human brain functional anatomy during nonmotor learning. Cereb Cortex 4:8-26.

Ranganath C, Johnson MK, D'Esposito M (2000) Left anterior prefrontal activation increases with demands to recall specific perceptual information. J Neurosci 20:RC108(1-5).

Raz N (2000) Aging of the brain and its impact on cognitive performance: integration of structural and functional findings. In: The handbook of aging and cognition (Craik FIM, Salthouse TA, eds), pp 1-90. Mahwah, NJ: Lawrence Erlbaum.

Raz N, Gunning FN, Head D, Dupuis JH, McQuain J, Briggs SD, Loken WJ, Thornton AE, Acker JD (1997) Selective aging of the human cerebral cortex observed in vivo: differential vulnerability of the prefrontal gray matter. Cereb Cortex 7:268-282.
Reuter-Lorenz PA (2002) New visions of the aging mind and brain. Trends Cogn Sci 6:394-400.

Reuter-Lorenz PA, Jonides J, Smith EE, Hartley A, Miller A, Marshuetz C, Koeppe RA (2000) Age differences in the frontal lateralization of verbal and spatial working memory revealed by PET. J Cognit Neurosci 12:174-187.

Rubin DC (1999) Frontal-striatal circuits in cognitive aging: evidence for caudate involvement. Aging Neuropsychol Cognit 6:241-259.

Schacter DL (1987) Memory, amnesia, and frontal lobe dysfunction. Psychobiology 15:21-36.

Schacter DL, Buckner RL, Koutstaal W, Dale AM, Rosen BR (1997) Late onset of anterior prefrontal activity during true and false recognition: an event-related fMRI study. NeuroImage 6:259-269.

Schneider W, Shiffrin RM (1977) Controlled and automatic human information processing: I. Detection, search, and attention. Psychol Rev 84:1-66.

Scoville WB, Milner B (1957) Loss of recent memory after bilateral hippocampal lesions. J Neurol Neurosurg Psychiatry 20:11-21.

Shimamura AP, Janowsky JS, Squire LR (1991) What is the role of frontal lobe damage in memory disorders? In: Frontal lobe function and dysfunction (Levin HS, Eisenberg HM, Benton AL, eds), pp 173-195. New York: Oxford UP.

Squire LR (1992) Memory and the hippocampus: a synthesis from findings with rats, monkeys, and humans. Psychol Rev 99:195-231.

Strange BA, Henson RN, Friston KJ, Dolan RL (2001) Anterior prefrontal cortex mediates rule learning in humans. Cereb Cortex 11:1040-1046.

Thompson-Schill SL, D’Esposito M, Aguirre GK, Farah MJ (1997) Role of left inferior prefrontal cortex in retrieval of semantic knowledge: a reevaluation. Proc Natl Acad Sci USA 94:14792-14797.

Tulving E, Pearlstone Z (1966) Availability versus accessibility of information in memory for words. J Verbal Learn Verbal Behav 5:381-391.

Tulving E, Kapur S, Craik FIM, Moscovitch M, Houle S (1994) Hemispheric encoding/retrieval asymmetry in episodic memory: positron emission tomography findings. Proc Natl Acad Sci USA 91:2016-2020.

Wagner AD, Poldrack RA, Eldridge LL, Desmond JE, Glover GH, Gabrieli JD (1998) Material-specific lateralization of prefrontal activation during episodic encoding and retrieval. NeuroReport 9:3711-3717.

Wheeler MA, Stuss DT, Tulving E (1995) Frontal lobe damage produces episodic memory impairment. J Int Neuropsychol Soc 1:525-536.

Wheeler ME, Velanova K, Jacoby LL, Petersen SE, McAvoy MP, Buckner RL (2002) Neural correlates of controlled retrieval: a mixed block/eventrelated analysis. Soc Neurosci Abstr 28:582.2.

Wheeler ME, Buckner RL (2003) Functional dissociation among components of remembering: control, perceived oldness, and content. J Neurosci 23:3869-3880.

Winocur G, Moscovitch M (1990) Hippocampal and prefrontal cortex contributions to learning and memory-analysis of lesion and aging effects on maze-learning in rats. Behav Neurosci 104:544-551.

Zacks RT, Hasher L (1994) Directed ignoring: inhibitory regulation of working memory. In: Inhibitory processes in attention, memory, and language (Dagenbach D, Carr TH, eds), pp 242-264. San Diego, CA: Academic. 